\title{
A Macromolecular Synthesis-Dependent Late Phase of Long-Term Potentiation Requiring CAMP in the Medial Perforant Pathway of Rat Hippocampal Slices
}

\author{
Peter V. Nguyen and Eric R. Kandel \\ The Howard Hughes Medical Institute and Center for Neurobiology and Behavior, College of Physicians and Surgeons of \\ Columbia University, New York, New York 10032
}

\begin{abstract}
Memory storage consists of a short-term phase that is independent of new protein synthesis and a long-term phase that requires the synthesis of new proteins and RNA. A cellular representation of these two phases has been demonstrated recently for long-term potentiation (LTP) in both the Schaffer collateral and the mossy fibers of the hippocampus, a structure widely thought to contribute to memory consolidation. By contrast, much less information is available about the medial perforant pathway (MPP), one of the major inputs to the hippocampus. We found that both a short-lasting and a long-lasting potentiation (L-LTP) can be induced in the MPP of rat hippocampal slices by applying repeated tetanization in reduced levels of magnesium. This potentiation was dependent on the activation of NMDA receptors. The early, transient phase of LTP
\end{abstract}

in the MPP did not require either protein or RNA synthesis, and it was independent of protein kinase $A$ activation. By contrast, L-LTP required the synthesis of proteins and RNA, and was selectively blocked by inhibitors of CAMP-dependent protein kinase (PKA). Forskolin, an adenylate cyclase activator, also induced a L-LTP that was attenuated by inhibition of transcription. Our results demonstrate that, like LTP in the Schaffer collateral and mossy fiber pathways, MPP LTP also consists of a late phase that is dependent on protein and RNA synthesis and PKA activity. Thus, cAMP-mediated transcription appears to be a common mechanism for the late form of LTP in all three pathways within the hippocampus.

Key words: LTP; hippocampus; synaptic plasticity; gene expression; cAMP; protein kinase $A$
Cognitive psychological studies indicate that memory has stages and is commonly divided into at least two distinct temporal phases: short-term memory, which lasts for minutes to hours, and long-term memory, which can persist for days, weeks, or even longer (for review, see Polster et al., 1991). A transient application of inhibitors of mRNA and protein synthesis selectively blocks induction of long-term memory without affecting short-term memory (Davis and Squire, 1984; Castellucci et al., 1989; Crow and Forrester, 1990; Tully et al., 1994). In contrast to its induction, the maintenance of long-term memory, once established, does not rcquirc macromolecular synthesis (Davis and Squire, 1984). Molecular studies of memory storage for implicit and explicit forms of memory suggest that in both cases the consolidation, or switch, from short-term to long-term memory involves the induction of genes and proteins.

Studies of the transition from short-term to long-term memory in invertebrates have provided evidence that the switch can be defined on the molecular level. In the marine snail, Aplysia, studies of memory for sensitization of the gill- and siphonwithdrawal reflexes have revealed mechanistic differences at the cellular level. The connections between the sensory and motor

Received Nov. 27, 1995; revised Feb. 23, 1996; accepted Feb. 26, 1996.

This work was supported by the Howard Hughes Medical Institute (E.R.K.), National Institute on Aging Center for Alzheimer's Diseasc Research Grant AG08702, and National Institute of General Medical Sciences Grant GM32099. P.V.N. is a Fellow of the Medical Research Council of Canada. E.R.K. is Senior Investigator of the Howard Hughes Medical Institute. We thank Mark Mayford, Steve Siegelbaum, and Yan-You Huang for constructive comments on this manuscript, and Harrict Ayers and Chuck Lam for preparing this manuscript.

Correspondence should be addressed to Dr. Peter Nguyen, Howard Hughes Medical Institute, 722 West 168th Street, New York, NY 10032.

Copyright (c) 1996 Socicty for Neuroscience 0270-6474/96/163189-10\$05.00/0 cells show a distinction between short-term and long-term retention of presynaptic facilitation (a mechanism contributing to sensitization). The short-term enhancement of synaptic strength occurs by means of post-translational modification of preexisting proteins and is mediated by both cAMP-dependent protein kinase (PKA) and protein kinase C (PKC) (Castellucci et al., 1980; Montarolo et al., 1986; Ghirardi et al., 1992; Byrne et al., 1993). The long-term process requires new protein synthesis and CAMPmediated gene expression through the activation of CREB-1 and the relief from repression of CREB-2 (Montarolo et al., 1986; Dash et al., 1990; Alberini et al., 1994; Bartsch et al., 1995) and leads to the growth of new synaptic connections (Glanzman et al., 1990; Nazif et al., 1991). Similarly, studies of Drosophila indicate that learning and short-term memory require PKA and that longterm memory requires gene expression initiated by CREB (Tully et al., 1994; Yin et al., 1994).

Recent experiments suggest that similar mechanisms may be involved in explicit memory storage in the mammalian brain. Explicit forms of learning involve the acquisition of information about people, places, and things, and are critically dependent on structures within the temporal lobe, including the hippocampus. Within the hippocampus, there are three prominent serial synaptic pathways and several minor ones (Andersen et al., 1971; Amaral, 1993). Input to the hippocampus originates from neurons of the entorhinal cortex by way of the perforant pathway (lateral and medial), which synapses onto granule cells of the dentate gyrus. The granule cells send their axons (the mossy fibers) to synapse on pyramidal cells of area CA3. Finally, CA3 pyramidal cells send their axons (the Schaffer collaterals) to other pyramidal cells in area CA1. Damage to any one of these three serial 
pathways is thought to be sufficient to produce some memory impairment in humans (Zola-Morgan et al., 1986).

Hippocampal ncurons are known to undergo long-lasting increases in synaptic strength after brief, high-frequency stimulation of any one of the three major pathways (Bliss and Lømo, 1973) (for review, see Bliss and Collingridge, 1993). In freely moving animals, the activity-dependent increase in synaptic strength can last for hours or even days, and is called long-term potentiation (LTP).

LTP has been most extensively studied in hippocampal slices (Andersen et al., 1977). These studies have revealed important differences in the induction mechanisms for LTP in the three pathways (for review, see Bliss and Collingridge, 1993). As with behavioral memory, LTP in the CA1 and CA3 regions consists of two biochemically distinct temporal phases. There is an early phase, lasting 1-3 hr, that is independent of protein and RNA synthesis, and a later, more persistent phase that requires new protein and RNA synthesis and is mediated by cAMP (Frey et al., 1993; Matthies and Reymann, 1993; Huang and Kandel, 1994; Huang et al., 1994; Nguyen et al., 1994).

Is there also a late phase of LTP in the perforant pathway of hippocampal slices? Would such a late phase also require the participation of cAMP, the synthesis of proteins, and the induction of genes? Unlike LTP in the mossy fiber and Schaffer collateral pathways, LTP in the perforant pathway has been studied mostly in anesthetized or freely moving animals. Relatively fewer studies have examined LTP in the perforant pathway in acute hippocampal slices (for exceptions, see Hanse and Gustafsson, 1992a,b, 1994; Colino and Malenka, 1993), and these studies have not addressed later stages ( $>1 \mathrm{hr}$ after induction) or explored the possible involvement of protein synthesis and gene induction in these phases (but for in vivo data see Krug et al., 1984; Cole et al., 1989; Otani et al., 1989; Qian et al., 1993).

In the present study, we have examined the medial perforant pathway (MPP) in rat hippocampal slices and have found that a long-lasting potentiation (L-LTP) of synaptic transmission can be induced by repeated, strong tetanization of this pathway in the presence of lowered extracellular magnesium. This L-LTP was selectively blocked by inhibitors of protein and RNA synthesis, whereas an early, transient phase of LTP remained unaffected by these same inhibitors. We also found that inhibition of PKA blocks the later phase of LTP, without affecting the early phase. Our results, taken together with the data from areas CA1 and CA3 of the hippocampus and from Aplysia (Frey et al., 1993; Alberini et al., 1994; Huang and Kandel, 1994; Huang et al., 1994; Nguyen et al., 1994), support the notion that common mechanisms of long-term synaptic facilitation, involving cAMP and the synthesis of new proteins and mRNA, may underlie cellular representations of the conversion of short-term to long-term memory for several different forms of learning in both vertebrates and invertebrates.

\section{MATERIALS AND METHODS}

Transversely cut hippocampal slices (400 $\mu \mathrm{M}$ thickness) were prepared from Sprague-Dawley rats (35-45 d old) using conventional procedures and were maintained in an interface chamber at $28^{\circ} \mathrm{C}$. Slices were continuously superfused at $1 \mathrm{ml} / \mathrm{min}$ with a solution bubbled with carboxygen $\left(95 \% \mathrm{O}_{2} / 5 \% \mathrm{CO}_{2}\right.$ ) and containing (in $\mathrm{mm}$ ): $124 \mathrm{NaCl}, 1.3$ $\mathrm{MgSO}_{4}, 4.4 \mathrm{KCl}, 26 \mathrm{NaHCO}_{3}, 2.5 \mathrm{CaCl}_{2}, 1 \mathrm{NaII}_{2} \mathrm{PO}_{4}$, and 10 glucose. Slices were allowed to recover for $90 \mathrm{~min}$ before recordings were attempted. For extracellular stimulation of the MPP, a bipolar nickelchromium electrode was placed in the middle molecular layer of the dentate gyrus (Hjorth-Simonsen and Jeune, 1972; Steward, 1976; McNaughton and Barnes, 1977). Extracellular field EPSPs were recorded with a glass microelectrode (4-7 $\mathrm{M} \Omega$ resistance) filled with perfusate and situated in the middle molecular layer of the dentate gyrus. Medial pathway responses were confirmed on the basis of depression of field EPSPs elicited with paired pulses spaced $40-100 \mathrm{msec}$ apart (McNaughton, 1980). Slices that showed maximum field EPSP sizes of $<3 \mathrm{mV}$ were rejected. For LTP cxperiments, the stimulation intensity was adjusted to give baseline field EPSP slopes $\sim 40 \%$ of maximal evoked slopes. Test stimuli ( 0.05 msec pulse width) were delivered at $0.02 \mathrm{~Hz}$ before tetanization. LTP was induced using 3 or 10 trains of $100 \mathrm{~Hz}$ (1 scc duration) delivered once/min. The stimulus strength during tetanization was in creased by doubling the pulse width to $0.1 \mathrm{msec}$. Picrotoxin was not used, and lowered (0.7 mM) $\mathrm{MgSO}_{4}$ was present in all experiments, unless otherwise indicated. All drugs were made fresh in perfusate, except for forskolin (0.1\% DMSO final concentration), actinomycin-D $(0.05 \%$ ethanol final concentration), and KT-5720 (0.1\% DMSO final concentration). Control baseline experiments for forskolin and actinomycin-D (ACT-D) were carried out in the presence of perfusate with $0.1 \%$ DMSO (for forskolin and KT-5720) or 0.05\% cthanol (for ACT-D). Student's unpaired $t$ test was used for statistical comparisons of mean field EPSP slopes in all experiments.

\section{RESULTS}

\section{Repeated strong tetanization in lowered magnesium induces L-LTP in the MPP}

As an initial step toward determining what conditions would be successful for inducing L-LTP in the MPP, we tried eliciting LTP in the presence of $50 \mu \mathrm{M}$ picrotoxin, a $\mathrm{GABA}_{\mathrm{A}}$ antagonist. A previous study had shown that in the absence of pharmacological disinhibition (by picrotoxin), little potentiation could be reliably induced in the perforant pathway (Wigström and Gustafsson, 1983a,b). With just two $100 \mathrm{~Hz}$ trains of test strength (spaced 20 sec apart), we were able, in the presence of picrotoxin, to induce LTP that lasted for $3 \mathrm{hr}$. However, sample field EPSP sweeps showed multiple evoked afterdischarges (Fig. 1A) at all times during LTP maintenance. Such epileptiform activity was unsatisfactory for our experiments, which were aimed at testing for a critical requirement for translation and transcription in expression of L-LTP. Because macromolecular synthesis can be modulated and activated by electrical activity in neurons, the continual epileptiform afterdischarges seen with picrotoxin ruled out further use of this potent GABA antagonist.

LTP in the MPP of rat hippocampal slices is dependent on NMDA receptor activation (Hanse and Gustafsson, 1992b; Colino and Malenka, 1993). We therefore decided to reduce the saline level of magnesium to $50 \%$ of normal valucs and apply varying numbers of $100 \mathrm{~Hz}$ trains (1 sec duration, twice test strength) to the MPP.

In the presence of reduced magnesium, three $100 \mathrm{~Hz}$ trains (delivered once $/ \mathrm{min}$ ) elicited a short-lasting potentiation that decayed after $70 \mathrm{~min}$ to $128 \pm 4 \%$ of pretetanus baseline (Fig. $1 B$; $n=7$ ). Three hours after tetanization, the level of potentiation was $116 \pm 7 \%$ of baseline. By contrast, six $100 \mathrm{~Hz}$ trains, under the same conditions, induced a slightly more robust LTP that was significantly different in magnitude from that elicited by three trains (Fig. $1 B ; p<0.05$ for time points $90 \mathrm{~min}$ after tetanization). However, there was greater variability in the magnitude of the potentiation seen with six trains: 3 of 7 slices tested failed to maintain the level of potentiation above $150 \%$ of pretetanus baseline for the $3 \mathrm{hr}$ duration of these experiments. We therefore sought an even stronger induction protocol to reliably induce a robust potentiation that would persist for $3 \mathrm{hr}$.

Using the same ionic conditions $(50 \% \mathrm{Mg}$, normal calcium), we next applied 10 trains of stimulation to the MPP (twice test strength, delivered once/min). We found that this protocol induced a very robust and stable form of LTP that persisted for at 

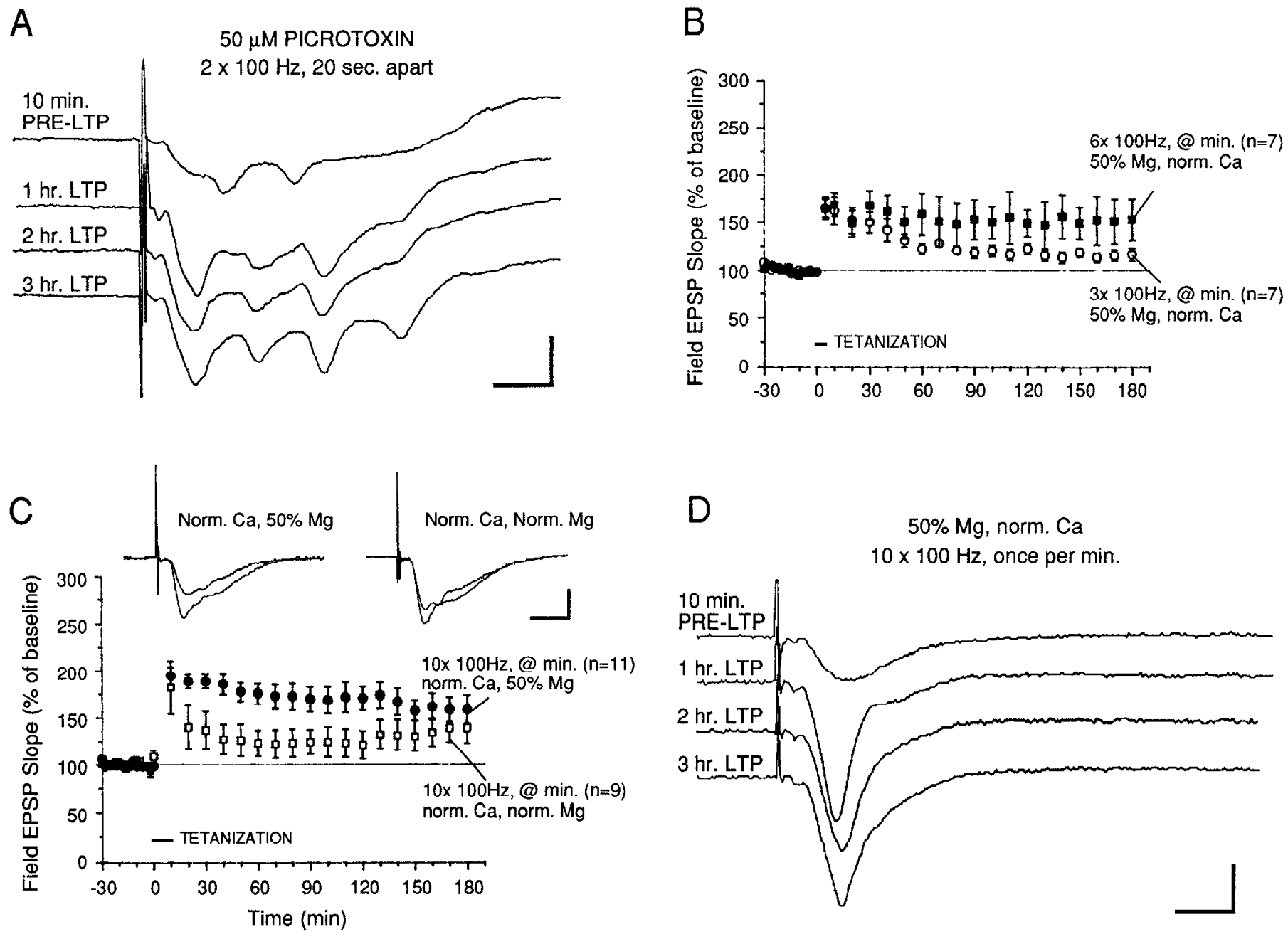

Figure 1. Repeated tetanization induces short- or long-lasting potentiation (L-LTP) in the MPP. $A$, In the continual presence of $50 \mu \mathrm{M}$ picrotoxin, two $100 \mathrm{~Hz}$ trains ( $20 \mathrm{sec}$ apart) elicited L-LTP but also induced repetitive afterdischarges after evoked field EPSPs. Sample traces were recorded from a slice at times indicated. Calibration bars: $2 \mathrm{mV}, 4 \mathrm{msec} . B$, Short-lasting potentiation was induced by three $100 \mathrm{~Hz}$ trains applied once every minute (at twice test pulse width) starting at " 0 min" on the graph. With this protocol, the level of facilitation decayed to $<125 \%$ of baseline $60-90$ min after tetanization. With six trains of $100 \mathrm{~Hz}$ stimulation, a longer-lasting potentiation was induced that, although persistent, was variable in magnitude: 3 of 7 slices tested showed $<50 \%$ facilitation $60 \mathrm{~min}$ after tetanization. In both protocols, normal calcium and $50 \%$ of normal magnesium levels were present in the saline. $C$, Ten $100 \mathrm{~Hz}$ trains induced a robust and persistent potentiation of MPP field EPSPs when applied in 50\% Mg saline (filled circles; $n=11$ ). In contrast, the same protocol elicited only a moderate level of facilitation in normal $\mathrm{Mg}$ saline (lower curve, open symbols). The levels of potentiation in normal $\mathrm{Mg}$ were significantly lower than those in the reduced $\mathrm{Mg}$ saline, beginning $20 \mathrm{~min}$ after tetanization and extending to $130 \mathrm{~min}$ after tetanization, and averaged only $122 \%$ of pretetanus baseline. Sample field EPSP traces were recorded $10 \mathrm{~min}$ before and $2 \mathrm{hr}$ after tetanization. Calibration bars: $2 \mathrm{mV}, 4 \mathrm{msec} . D$, Sample field EPSP traces measured from a slice that had been tetanized in reduced $\mathrm{Mg}$ saline showed robust potentiation and no repetitive afterdischarges (compare with $A$ ). Calibration bars: $2 \mathrm{mV}, 4 \mathrm{msec}$.

least $3 \mathrm{hr}$ after tetanization. The mean levels of potentiation recorded 1,2 , and $3 \mathrm{hr}$ after tetanization were $175 \pm 11,170 \pm 12$, and $158 \pm 15 \%$ of pretetanus baseline, respectively (Fig. $1 C ; n=$ 11). In some slices, this potentiation lasted $7 \mathrm{hr}$ (P. Nguyen, unpublished observations). In contrast, the level of facilitation induced by 10 trains in the presence of normal magnesium and calcium levels was $123 \pm 14,121 \pm 15$, and $139 \pm 17 \%$ after 1,2 and $3 \mathrm{hr}$, respectively (Fig. $1 C ; p<0.02$ for 1 and $2 \mathrm{hr}$ values). Hence, the 10 train induction protocol in lowered magnesium proved to bc the most rcliablc for inducing a stablc and robust form of L-LTP in the MPP. Examination of sample field EPSP sweeps recorded during LTP maintenance (Fig. 1D) showed further that this 10 train regimen did not elicit epileptiform discharges in any of the 11 slices tested. Thus, we decided to use this induction regimen for the remainder of our experiments on L-LTP in the MPP.

\section{LTP in the MPP is NMDA receptor-dependent}

Previous studies on LTP in the MPP of hippocampal slices have shown that NMDA receptor activation is necessary for induction of LTP (Hanse and Gustafson, 1992b; Colino and Malenka, 1993). Those studies used picrotoxin and an induction regimen different from ours; hence, we tested whether the form of LTP induced by our present protocol (ten $100 \mathrm{~Hz}$ trains in reduced magnesium) also was NMDA receptor-dependent.

In the presence of the NMDA receptor antagonist 2-amino-5phosphonovaleric acid (APV; $100 \mu \mathrm{M})$, no potentiation was induced by ten $100 \mathrm{~Hz}$ trains in reduced magnesium levels (Fig. 2; 
Figure 2. MPP LTP induced by repeated tetanization is dependent on NMDA receptor activation. The NMDA receptor antagonist APV $(100 \mu \mathrm{M})$ blocked potentiation when applied for $30 \mathrm{~min}$ beginning $20 \mathrm{~min}$ before the start of tetanization. The first recorded response after tetanus was obtained $1 \mathrm{~min}$ after the last of ten $100 \mathrm{~Hz}$ trains (delivered once/min at twice test pulse width); hence, no post-tetanic potentiation was observed. All experiments were performed using saline containing $50 \%$ of normal $\mathrm{Mg}$ levels.

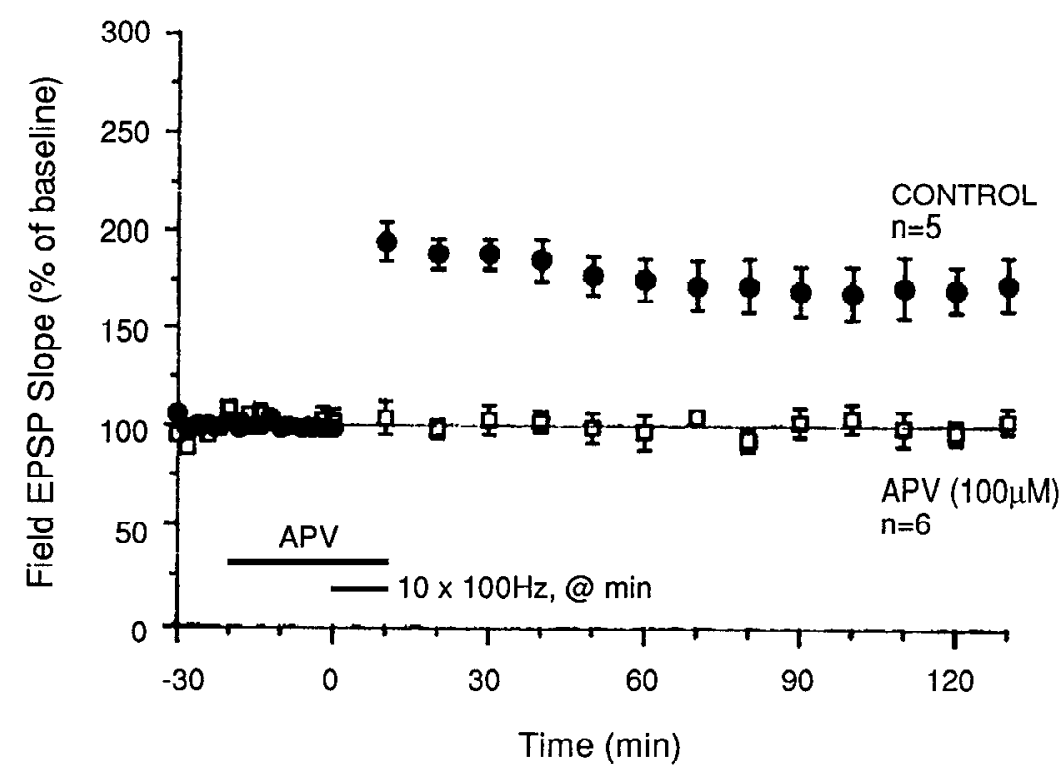

the early stages. In the case of ACT-D, the levels of potentiation in drug-treated slices were significantly lower than in controls from $80 \mathrm{~min}$ after tetanization onward (Fig. $4 A 1 ; p<0.05$ ). The levels of potentiation $3 \mathrm{hr}$ after tetanization were $182 \pm 16 \%$ of baseline in controls and $130 \pm 10 \%$ in drug-treated slices (Fig. $4 A 1 ; p<0.05$ ). For DRB, we observed a slightly more gradual decay of L-LTP. Levels of potentiation in DRB-treated slices were significantly lower than those in controls beginning only from $100 \mathrm{~min}$ after tetanization (Fig. $4 B 1 ; p<0.05$ for all time points thereafter). The levels of facilitation in controls and DRB-treated slices $3 \mathrm{hr}$ after tetanization were $161 \pm 11$ and $118 \pm 8 \%$, respectively (Fig. $4 B 1 ; p<0.05$ ). Thus, at concentrations that have been shown previously to effectively block transcription in hippocampal slices (see Nguyen et al., 1994), these two transcriptional inhibitors (which act through different mechanisms of block) significantly attenuated the late phase of LTP, without affecting the early stages, in the MPP.

\section{Repeated tetanization of the MPP induces a PKA-dependent late phase of LTP}

Earlier work has shown that cAMP-dependent protein kinase activity is critical for expression of the late, but not the early, phase of LTP in the Schaffer collateral pathway (Frey et al., 1994; Huang and Kandel, 1994) and in the mossy fiber pathway (Huang et al., 1994). Is the late phase of LTP in the MPP also dependent on PKA activity?

To address this question, we tested the effects of two inhibitors of PKA, Rp-cAMPs and KT-5720, which act on the regulatory and on the catalytic subunits specifically. After a $40 \mathrm{~min}$ exposure to 50 $\mu \mathrm{M}$ Rp-cAMPS (beginning $15 \mathrm{~min}$ before initiation of tetanization), potentiation in drug-treated slices was significantly attenuated from $30 \mathrm{~min}$ after tetanization (ten $100 \mathrm{~Hz}$ trains), as compared with control slices that had been tetanized only (Fig. $5 A 1 ; p$ $<0.05$ for all limes from $30 \mathrm{~min}$ after tetanization). KT-5720, applicd for $25 \mathrm{~min}$, beginning $15 \mathrm{~min}$ before tetanization, also significantly reduced potentiation in drug-treated slices (Fig. 6A1; $p<0.05$ for all times from $50 \mathrm{~min}$ after tetanization). For both inhibitors, the levels of potentiation observed $3 \mathrm{hr}$ after tetanization were $99 \pm 9 \%(\mathrm{Rp}$-cAMPS) and $108 \pm 11 \%(\mathrm{KT}-5720)$ of ribofuranosyl benzimidazole (DRB), two inhibitors of transcription, significantly attenuated a late stage of LTP without affecting

\section{The late phase of LTP in the MPP is mediated by transcription}

We also tested whether gene transcription was required for expression of L-LTP in the MPP. Acute exposure of hippocampal slices to either $40 \mu \mathrm{M}$ ACT-D or $0.2 \mathrm{mM} 5$,6-dichloro-1- $\beta$-D- 


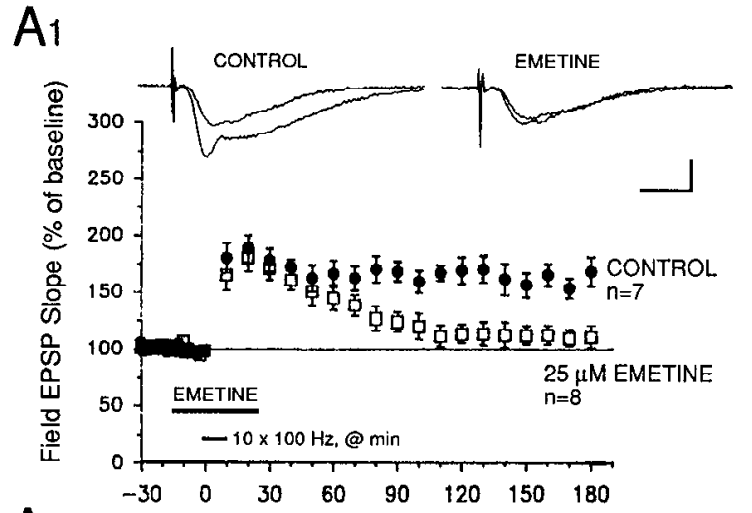

$\mathrm{A}_{2}$
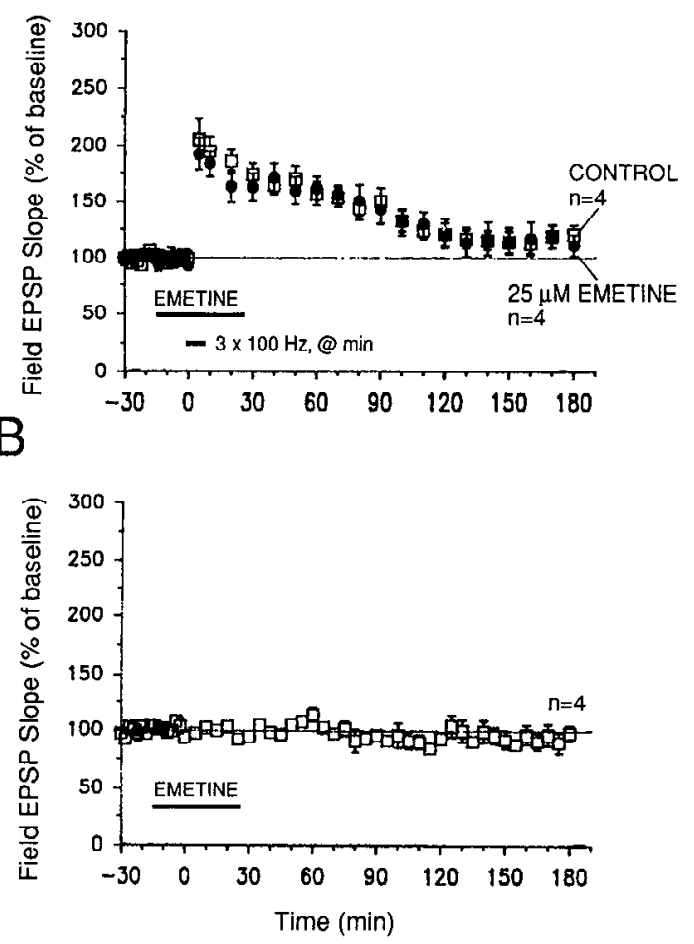

Figure 3. The late phase of LTP in the MPP requires protein synthesis. $A 1$, Potentiation induced by ten $100 \mathrm{~Hz}$ trains (delivered once/min at twice test pulse width) was significantly attenuated in slices exposed to $25 \mu \mathrm{M}$ emetine (a protein synthesis inhibitor) for $40 \mathrm{~min}$. The early phase of LTP extending from immediately after tetanization until $\sim 70$ min after tetanization, was unaffcctcd by cmctinc. Sample field EPSP traces were recorded $10 \mathrm{~min}$ before and $3 \mathrm{hr}$ after tetanization. Scale bars: $2 \mathrm{mV}, 4 \mathrm{msec}$. $A 2$, Emetine $(25 \mu \mathrm{M})$ had no effect on short-lasting potentiation induced by three $100 \mathrm{~Hz}$ trains (delivered once/min at twice test pulse width) Controls, open symbols; emetine, filled symbols. $B$, Acute application of 25 $\mu \mathrm{M}$ emetine for $40 \mathrm{~min}$ had no marked effects on baseline field EPSPs evoked at $0.02 \mathrm{~Hz}$

baseline; in untreated controls, these values were $158 \pm 15$ and $149 \pm 10 \%$ of baseline, respectively (Figs. $5 A 1,6 A 1 ; p<0.05$ ).

In contrast to their attenuation of L-LTP, both Rp-cAMPS and $\mathrm{KT}-5720$ had no significant effects on short-lasting potentiation elicited with only three $100 \mathrm{~Hz}$ trains of stimulation (Figs. $5 \mathrm{A2}$, $6 A 2$ ). Slices that were treated with either inhibitor showed potentiation that decayed back to $100-110 \%$ of pretetanus baseline within $3 \mathrm{hr}$ after tetanization. Control slices that were not exposed to inhibitors also showed a gradually decaying potentiation that was not significantly different in magnitude from that observed in treated slices (Figs. 5A2, 6A2;p>0.5 for all points in both graphs).

Our findings show that, like L-LTP in the mossy fiber and Schaffer collateral pathways, the late phase of LTP in the MPP also requires PKA activity for full expression. Furthermore, shortlasting potentiation induced by fewer trains does not require PKA activity.

\section{Forskolin, an adenylate cyclase activator, induces a transcription-dependent form of L-LTP in the MPP}

To explore the possibility that L-LTP in the MPP can be simulated by activation of the cAMP signaling pathway, we applied forskolin (an activator of adenylate cyclase) to slices during $0.02 \mathrm{~Hz}$ tcst stimulation of the MPP. A $15 \mathrm{~min}$ application of $50 \mu \mathrm{M}$ forskolin potentiated field EPSPs evoked by MPP stimulation: mean field EPSP slopes recorded 1, 2, and $3 \mathrm{hr}$ after forskolin application were $148 \pm 9,158 \pm 12$, and $160 \pm 11 \%$ of preforskolin baseline, respectively (Fig. $7 A ; n=7$ ). These values were significantly greater than those recorded from slices treated with an equal concentration of an inactive forskolin analog $(7 \beta$-deacetyl- $7 \beta-[\gamma$ (morpholino)butyryl]hydrochloride) (Fig. $7 B ; p<0.01$ for all time points from $45 \mathrm{~min}$ after forskolin). The inactive forskolin analog did not exert significant effects on baseline field EPSP slopes over the $3 \mathrm{hr}$ recording period (Fig. $7 B ; n=4$ ).

Is gene transcription necessary for forskolin-induced facilitation of transmission in the MPP? Acute application of the transcriptional inhibitor ACT-D $(40 \mu \mathrm{M}, 1 \mathrm{hr})$ significantly attenuated the synaptic potentiation elicited by forskolin (Fig. $7 A$ ). The levels of potentiation in slices treated with ACT-D and forskolin $(50 \mu \mathrm{M}$, $15 \mathrm{~min}, n=7$ ) were $123 \pm 10$ and $126 \pm 6 \%$ at $90 \mathrm{~min}$ and $3 \mathrm{hr}$ after forskolin application, respectively. These values were significantly lower than those observed in slices treated with forskolin alone $(165 \pm 8$ and $160 \pm 11 \%$ at the same respective times; $n=$ $6, p<0.02)$.

These results reinforce those using inhibitors of PKA and demonstrate that activation of the cAMP signaling pathway by forskolin produces L-LTP of synaptic transmission in the MPP. They also suggest that once triggered (by a transient application of forskolin), the cAMP signal transduction pathway is capable of effecting persistent physiological changes that lead to long-lasting facilitation, even though forskolin is no longer present. Such persistent changes may involve the activation of cAMP-inducible genes and the initiation of pre- and/or postsynaptic structural changes.

\section{DISCUSSION}

\section{LTP in MPP has distinctive requirements for induction}

Cellular anatomical studies have established that the perforant pathway is divided into two major divisions: the lateral pathway forms excitatory synapses onto the outer one-third of the dentate granule cells' dendrites in the molecular layer, and the medial pathway forms excitatory synapses onto the middle third of these same dendrites (Hjorth-Simonsen and Jeune, 1972; Steward, 1976; McNaughton and Barnes, 1977). These two pathways can be distinguished by their physiological responses to paircd-pulse stimulation: the lateral pathway shows paired-pulse facilitation, whereas the medial pathway displays paired-pulse depression (McNaughton, 1980; Colino and Malenka, 1993).

Our study has cstablishcd that a long-lasting and robust LTP can be induced in lowered extracellular magnesium by application of repeated strong tetanization. Previous studies on LTP in the perforant pathway of hippocampal slices have shown that the 

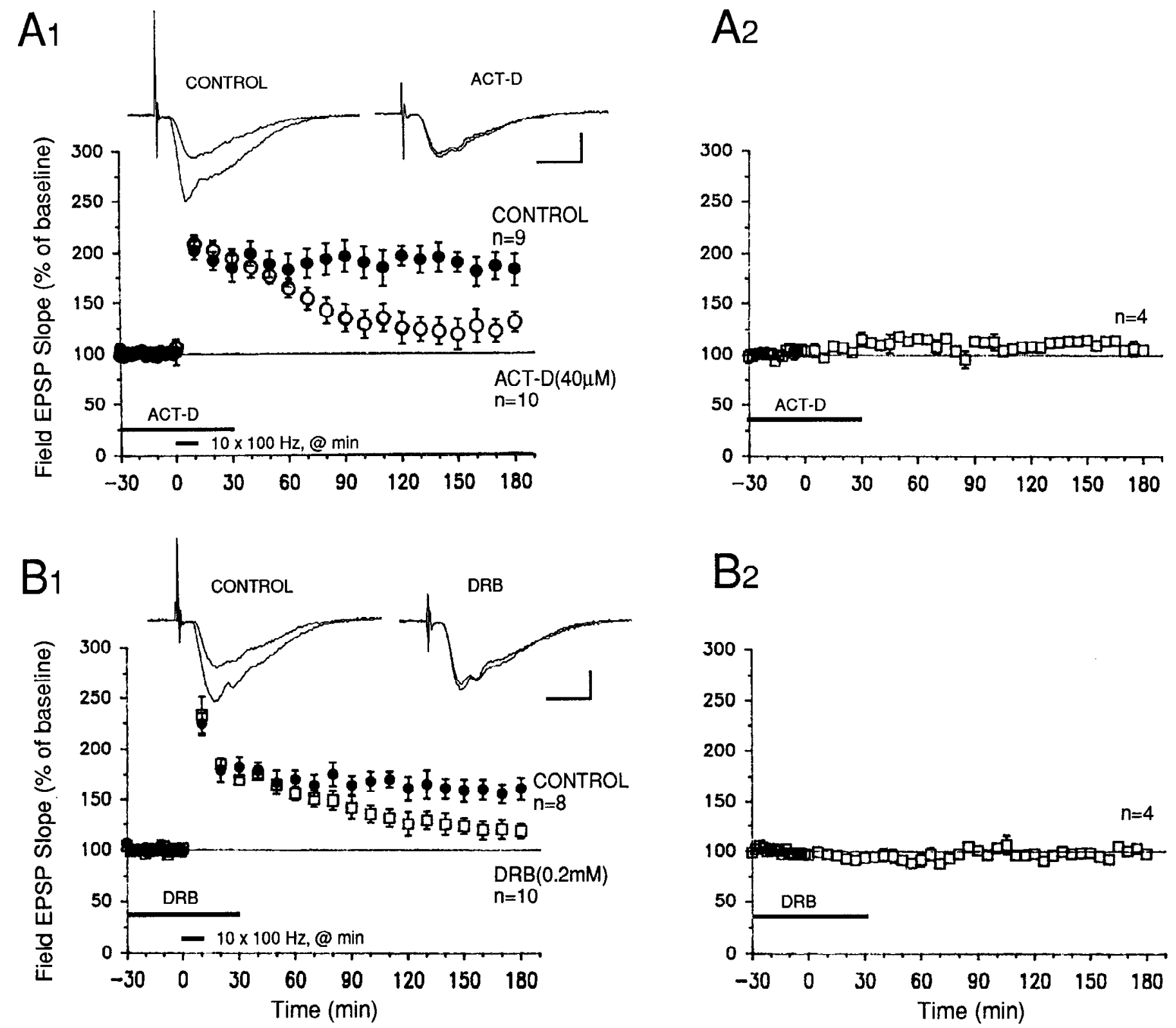

Figure 4. Gene transcription mediates the late phase of LTP in the MPP. A1, B1, Two different transcriptional inhibitors, actinomycin D (ACT D; 40 $\mu \mathrm{M})$ and DRB $(0.2 \mathrm{~mm})$, blocked expression of L-LTP when applied for $1 \mathrm{hr}$, beginning $30 \mathrm{~min}$ before start of tetanization. The levels of facilitation were significantly lower in drug-treated slices starting at $80 \mathrm{~min}$ after tetanus for ACT D $(A 1)$, and at $100 \mathrm{~min}$ after tetanus for DRB $(B 1)(p<0.05$ for unpaired $t$ test comparisons with control slices). Sample field EPSP traces were recorded 10 min before and $3 \mathrm{hr}$ after tetanization in both $A 1$ and $B 1$. Calibration bars for both graphs: $2 \mathrm{mV}, 4 \mathrm{msec}$. A2, B2, Neither $40 \mu \mathrm{M}$ ACT-D nor $0.2 \mathrm{mM}$ DRB significantly affected baseline field EPSPs evoked at 0.02 IIz. ACT $\mathrm{D}$ was dissolved in DMSO (0.1\% final concentration).

induction of robust LTP in the dentate gyrus is facilitated by pharmacological disinhibition by $\mathrm{GABA}_{\mathrm{A}}$ receptor antagonists (picrotoxin and bicuculline) (Wigström and Gustafsson, 1983a,b), and that in the absence of such disinhibition, little potentiation can be reliably induced in this area of the hippocampal slice (Wigström and Gustafsson, 1983a; Hanse and Gustafsson, 1993). This is consistent with the extensive synaptic inhibition present within the dentate gyrus (for review, see Soriano and Frotscher, 1993). We have not used pharmacological blockade of $\mathrm{GABA}_{\mathrm{A}}$ receptors to study L-LTP because, under our conditions of prolonged recording, exposure to picrotoxin $(50 \mu \mathrm{M})$ induced epileptiform activity after evoked responses. Such afterdischarges confounded the interpretation of results obtained during the maintenance phase of LTP, especially because transcription and translation are processes that can be activated and modulated by electrical activity (Cole et al., 1989; Sheng et al., 1990; Abraham et al., 1993; Qian et al., 1993). In contrast, lowered extracellular magnesium, which facilitates NMDA receptor activation, enhanced induction of L-LTP under our conditions, without cliciting repetitive afterdischarges or spontaneous epileptiform activity, as measured with extracellular electrodes.

Our study also extends the previous work of Hanse and Gustafsson (1992b) by showing that the amount and strength of tetanization determine the robustness and stability of LTP in the MPP of the dentate gyrus in hippocampal slices. Unlike our study, however, Hanse and Gustafsson (1992b) used picrotoxin and 


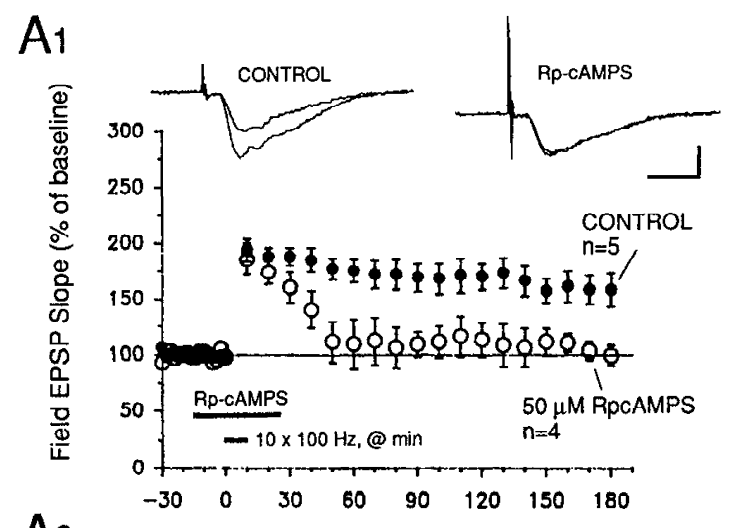

$\mathrm{A}_{2}$

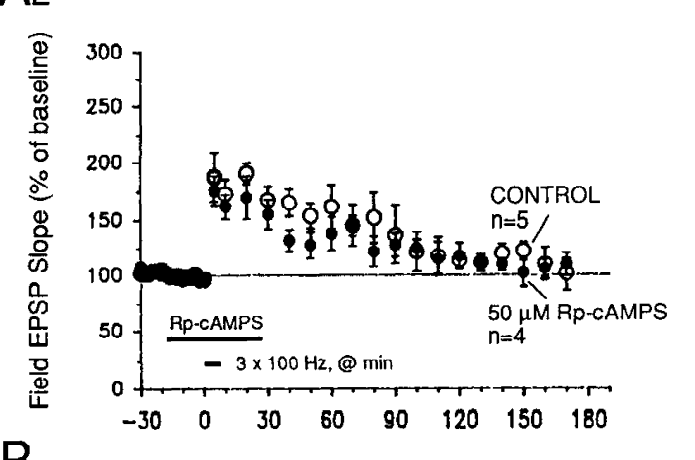

B

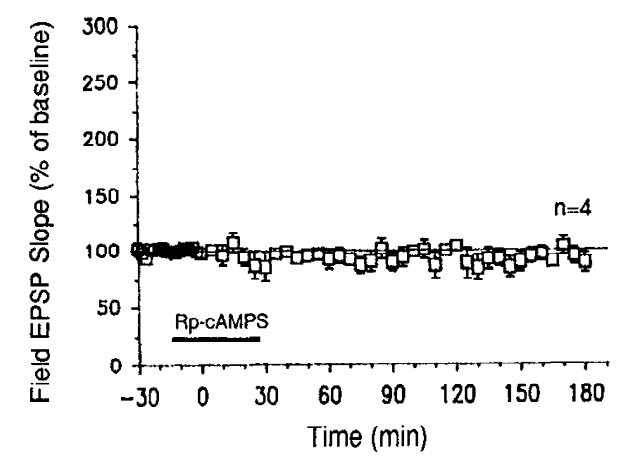

Figure 5. Rp-cAMPS, an inhibitor of PKA, blocks expression of the late phase of LTP in the MPP of hippocampal slices. A1, Slices treated with 50 $\mu \mathrm{M}$ Rp-cAMPS for $40 \mathrm{~min}$, beginning $15 \mathrm{~min}$ before tetanization, showed decaying LTP that was significantly less than the potentiation observed in untreated control slices $30 \mathrm{~min}$ after tetanization and thereafter. Application of Rp-cAMPS overlapped with the tetanization protocol (ten 100 $\mathrm{Hz}$ trains, delivered once/min at twice the test pulse width). Sample sweeps were taken $10 \mathrm{~min}$ bcfore tctanization and $3 \mathrm{hr}$ after the first tetanus. Calibration bars: $2 \mathrm{mV}, 4 \mathrm{msec}$. $A 2$, Short-lasting potentiation induced by three $100 \mathrm{~Hz}$ trains (delivered once/min at twice test pulse width) is unaffected by $50 \mu \mathrm{M}$ Rp-cAMPS. Rp-cAMPS was applied using the same time window as for the L-LTP graph of part $A 1$. Controls, Open symbols. $B$, Rp-cAMPS $(50 \mu \mathrm{M})$ applied for $40 \mathrm{~min}$ had no significant effect on baseline field EPSP slopes evoked by $0.02 \mathrm{~Hz}$. stimulation of the MPP.

restricted their LTP measurements to only the first $10-60 \mathrm{~min}$ after tetanization.

\section{LTP in the MPP in hippocampal slices has both an early and a late phase}

Our findings demonstrate that LTP in the MPP of rat hippocampal slices has two distinct temporal phases that involve different molecular mechanisms for their expression. An early phase, last-

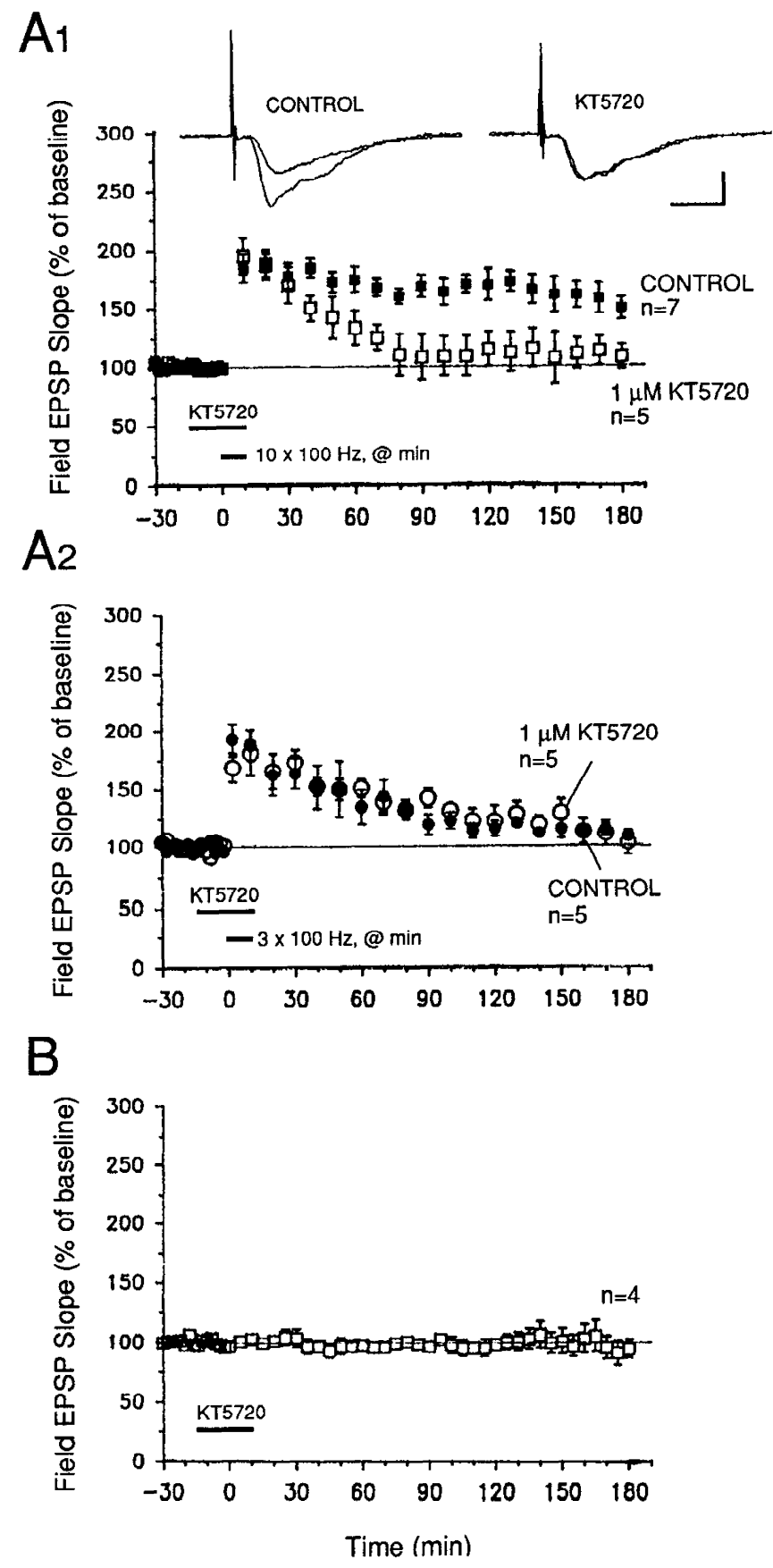

Figure 6. A second inhibitor of PKA, KT-5720, also prevents full expression of L-LTP in the MPP. A1, A 30 min application of $1 \mu \mathrm{M} \mathrm{KT}-5720$, beginning $15 \mathrm{~min}$ before tetanization, elicited a delayed decline of potentiation beginning 30-40 min after tetanization. Levels of facilitation in drug-treated slices were significantly lower than those in control slices beginning $60 \mathrm{~min}$ after tetanization $(p<0.05$ for $60 \mathrm{~min}$ after tetanization and all times thereafter). L-LTP was induced using the same protocol as in Figure 5. Sample field EPSP sweeps were recorded $10 \mathrm{~min}$ before and $3 \mathrm{hr}$ after the start of tetanization. Calibration bars: $2 \mathrm{mV}, 4 \mathrm{msec} . A 2$, Short-lasting facilitation induced by three $100 \mathrm{~Hz}$ trains (delivered once/ min at twice test pulse width) is unaffected by $1 \mu \mathrm{M}$ KT -5720 . The inhibitor was applied for the same time window as in part $A 1$ of this graph. Controls, Filled symbols. $B$, Acute exposure of slices to $1 \mu \mathrm{M} \mathrm{KT}-5720$ for $30 \mathrm{~min}$ had no effect on baseline field EPSPs evoked by $0.02 \mathrm{~Hz}$ stimulation of the MPP. KT-5720 was dissolved in DMSO (0.1\% final concentration). 


\section{A}

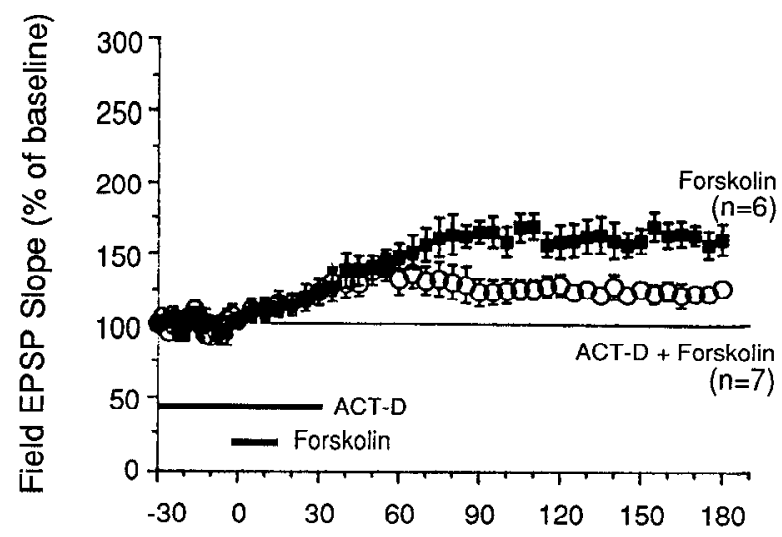

B

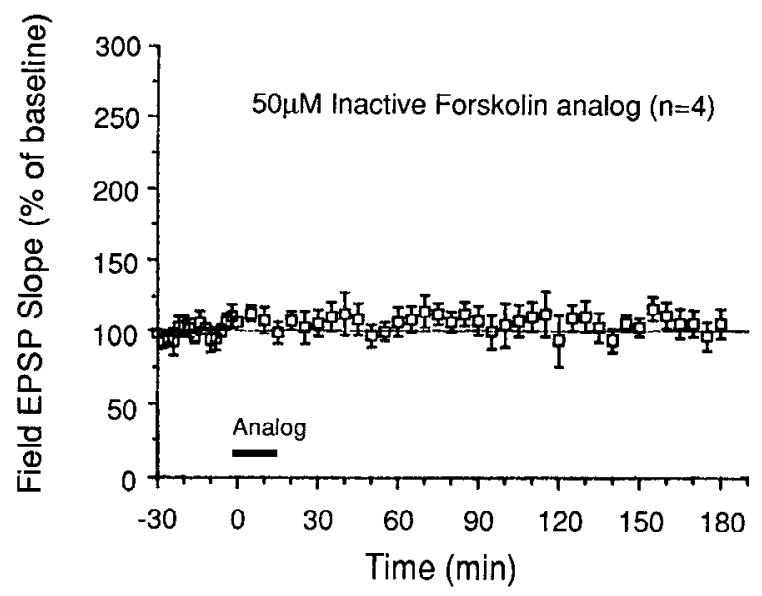

Figure 7. Activation of adenylyl cyclase by forskolin simulates late phase of I.TP in the MPP. A, Slices treated with $50 \mu \mathrm{M}$ forskolin for $15 \mathrm{~min}$ showed a gradual potentiation that reached a plateau level $\sim 45 \mathrm{~min}$ after forskolin application. This facilitation persisted for $3 \mathrm{hr}$ during 0.02 $\mathrm{Hz}$ test stimulation of the MPP. ACT D $(40 \mu \mathrm{M})$, a transcription inhibitor, attenuated this facilitation when applied before and during forskolin application. $B$, In contrast, $50 \mu \mathrm{M} 7 \beta$-deacetyl-7 $\beta-[\gamma$ (morpholino)butyryl]hydrochloride, an inactive forskolin analog, had no effect on baseline field EPSPs evoked at $0.02 \mathrm{~Hz}$. The analog was dissolved in DMSO (0.1\% final concentration). Normal magnesium and calcium levels were present in these experiments.

ing $\sim 45 \mathrm{~min}$, can be induced by three trains of high-frequency presynaptic impulses and does not require new protein or mRNA synthesis. By contrast, 10 trains produce a late phase (that emerges after the early phase) that is blocked by inhibitors of protein and RNA synthesis.

The exact mechanisms underlying the early phase of LTP in the MPP were not investigated in the present study, but previous work indicates that the level of postsynaptic (granule cell) depolarization, and thereby the level of postsynaptic $\mathrm{Ca}^{2+}$ influx, plays a critical role in governing the stability of the early phase of LTP (Hanse and Gustafsson, 1992a,b; Colino and Malenka, 1993). In addition, protein kinases appear to be critical for induction of the early phase, because staurosporine (a general kinase inhibitor) attenuates the early phase (Hanse and Gustafsson, 1994). In our experiments, inhibition of PKA did not abolish the early phase; thus, other kinases must underlie induction of the early phase.
Such kinases may include calcium/calmodulin-dependent protein kinase II, PKC, and tyrosine kinases.

\section{Similarities and differences in the early and late phases of LTP in all three regions of the hippocampus}

In light of recent work on LTP in hippocampal slices, it is worthwhile to compare the mechanisms underlying LTP in all three regions of the mammalian hippocampus. In the $\mathrm{CA} 1$ region, the early phase of Schaffer collateral LTP depends critically on the activities of the $\mathrm{Ca}^{2+} /$ calmodulin kinase, PKC, and tyrosine $\mathrm{ki}$ nases (for review, see Bliss and Collingridge, 1993). In the early phase of mossy fiber LTP PKA is involved (Huang et al., 1994; Weisskopf et al., 1994). In the MPP, the mechanisms underlying the early phase are unknown. Because inhibition of PKA did not reduce the early phase of LTP (present study), other kinases (e.g., $\mathrm{Ca}^{2+} /$ calmodulin kinase II) may be involved. Like Schaffer collateral LTP (but unlike mossy fiber LTP), induction of LTP in the MPP of the dentate gyrus occurs postsynaptically and requires activation of the NMDA receptor channel and $\mathrm{Ca}^{2+}$ influx in the postsynaptic cell (Nicoll et al., 1988; Zalutsky and Nicoll, 1990; Hanse and Gustafsson, 1992b; Colino and Malenka, 1993) (present study).

Unlike the early phase, the mechanisms for the late phase of LTP in all three regions appear to be very similar, at least in outline. In all three regions, the late phase requires new RNA and protein synthesis, as well as the participation of PKA (Frey et al., 1993; Matthies and Reymann, 1993; Huang and Kandel, 1994; Huang et al., 1994; Nguyen et al., 1994) (present study). These mechanisms for the late phasc of LTP in the hippocampus (which are involved in explicit forms of learning) resemble those used in Aplysia and Drosophila for storing behavioral long-term memory for implicit forms of learning (Montarolo et al., 1986; Dash et al., 1990; Drain et al., 1991; Alberini et al., 1994; Tully et al., 1994; Yin et al., 1994). This convergence of experimental data implies that different forms of learning may use a common, conserved class of molecular mechanisms for converting short-term memory into long-term memory: induction of genes by cAMP and PKA.

\section{Protein synthesis and the induction of L-LTP in the dentate gyrus}

Our finding that a late phase of LTP in the MPP of hippocampal slices is blocked by protcin synthcsis inhibition extends and consolidates previous work by others. Otani et al. (1989) and Krug et al. (1984) also reported a protein synthesis requirement for L-LTP in the dentate gyrus of anesthetized and freely moving rats. In these studies and in our present experiments, protein synthesis inhibitors did not affect expression of the early, transient phase of LTP, but attenuated late phases. Although we have not shown that emetine inhibited protein synthesis in dentate gyrus granule cells, an earlier study by Stanton and Sarvey (1984) has demonstrated that, at concentrations similar to that used in our present experiments, emetine strongly blocked protein synthesis in whole hippocampal slices.

Is the site of protein synthesis pre- or postsynaptic? Although whole-slice application of protein synthesis inhibitors does not permit a definitive localization of the cellular site of protein synthesis, a number of studies point to the postsynaptic granule cells as the probable locus of changes in protein synthesis. First, blockade of protein synthesis in the dentatc gyrus of anesthetized rats attenuated L-LTP, whereas inhibition in the entorhinal cortex (the site of the cell bodies of the presynaptic perforant path axons) had no effect on L-LTP (Otani and Abraham, 1989). Second, 
electrical stimulation leading to potentiation induces a plethora of mRNAs and proteins in dentate granule cells, including tissue plasminogen activator (tPA) (Qian et al., 1993) and other immediate-early genes (Cole et al., 1989; Hughes and Dragunow, 1995). Third, quantitative changes in protein synthesis in the dentate gyrus in vivo have been reported (Fazeli et al., 1993), although the identities of the proteins that change remain to be established. Finally, it should be noted that in the transverse hippocampal slice preparation, the cell bodies of the presynaptic perforant axons, situated in the entorhinal cortex, are absent. Furthermore, it is interesting to note that in area CA1 of hippocampal slices, only a transient carly phase of LTP is present in postsynaptic CA1 dendrites that were severed from CA1 pyramidal cell bodies (Frey et al., 1989). Hence, the cumulative evidence points to a postsynaptic site of gene and protein induction for L-LTP in the MPP.

\section{Are cAMP-inducible genes involved in L-LTP in the dentate gyrus?}

L-LTP in all three regions of the hippocampus requires transcription and can be simulated by forskolin-induced activation of the cAMP signal transduction pathway (Huang and Kandel, 1994; Huang et al., 1994; Nguyen et al., 1994; see also Chavez-Noriega and Stevens, 1994). Our observations that a transient application of forskolin induced a long-lasting form of potentiation that was attenuated by transcriptional inhibition, and that a late phase of LTP induced by repeated tetanization was also blocked by transcriptional inhibitors, raises the likely possibility that CAMPinducible gene expression is involved in mediating L-LTP in the MPP. Indeed, CREB and MAP kinase phosphorylation appear to be increased in the dentate gyrus after acute forskolin application to slices (Sarvey and Voulalas, 1995; Voulalas and Sarvey, 1995), and cAMP levels are increased transiently immediately after tetanization of the perforant path (Stanton and Sarvey, 1985). Our finding that PKA is critical for L-LTP induction further strengthens the idea that cAMP-induced gene expression, initiated by PKA-mediated phosphorylation of transcription factors such as CREB, is a critical component of the molecular machinery leading up to the establishment of the late phase of LTP in the MPP.

Which cAMP-inducible genes are activated during L-LTP in the hippocampus? In Aplysia, long-term (but not short-term) facilitation is accompanied by translocation of the catalytic subunit of PKA to the nucleus (Bacskai et al., 1993), where it appears to phosphorylate CREB-related transcription factors that activate a cascade of cAMP-inducible immediate-early genes (Dash et al., 1990; Kaang et al., 1993). One of the genes induced in the sensory neurons by cAMP is the Aplysia homolog of the mammalian transcription factor C/EBP (ApC/EBP) (Alberini et al., 1994). Blocking the function of $\mathrm{ApC} / \mathrm{EBP}$ in sensory neurons inhibits long-term, but not short-term, facilitation (Alberini et al., 1994). That the late phase of LTP in all three regions of the hippocampus also requires PKA activity raises the intriguing possibility that, in the hippocampus as well, cAMP and PKA are recruited to induce immediate-early genes that modulate and control the molecular machinery for expression of L-LTP. This molecular repertoire may involve the growth and differentiation of new synaptic connections (Desmond and Levy, 1986a,b; Bailey and Kandel, 1993).

\section{REFERENCES}

Abraham WC, Mason SE, Demoner J, Williams JM, Richardson CL, Tate WP, Lawlor PA, Dragunow M (1993) Correlations between immediate early gene induction and persistence of LTP. Neuroscience 56:717-727.
Alberini CM, Ghirardi M, Metz R, Kandel ER (1994) C/EBP is an immediate-early gene required for the consolidation of long-term facilitation in Aplysia. Cell 85:1099-1114.

Amaral DG (1993) Emerging principles of intrinsic hippocampal organization. Curr Opin Neurobiol 3:225-229.

Andersen P, Bliss TVP, Skrede KK (1971) Lamellar organization of hippocampal excitatory pathways. Exp Brain Res 13:222-238.

Andersen P, Sundberg SH, Sven O, Wigström H (1977) Specific longlasting potentiation of synaptic transmission in hippocampal slices. Nature 266:736-737.

Bacskai BJ, Hochner B, Mahaut-Smith M, Adams SR, Kaang B-K, Kandel ER, Tsien RY (1993) Spatially resolved dynamics of cAMP and protein kinase A subunits in Aplysia sensory neurons. Science 260:222-226.

Bailey CH, Kandel ER (1993) Structural changes accompanying memory storage. Annu Rev Physiol 55:397-426.

Bartsch D, Ghirardi M, Skehel PA, Karl KA, Herder SP, Chen M, Bailey CH, Kandel ER (1995) Aplysia CREB-2 represses long-term facilitation: relief of repression converts transient facilitation into long-term functional and structural change. Cell 83:979-992.

Bliss TVP, Collingridge GL (1993) A synaptic model of memory: longterm potentiation in the hippocampus. Nature 361:31-39.

Bliss TVP, LØmo T (1973) Long-lasting potentiation of synaptic transmission in the dentate area of the anaesthetized rabbit following stimulation of the perforant path. J Physiol (Lond) 232:331-356.

Byrne JH, Zwartjes R, Homayouni R, Critz SS, Eskin A (1993) Roles of second messenger pathways in neuronal plasticity and in learning and memory: insights gained from Aplysia. Adv Second Messenger Phosphoprotein Res 27:47-108.

Castellucci VF, Kandel ER, Schwartz JH, Wilson FD, Nairn AC, Greengard P (1980) Intracellular injection of the catalytic subunit of cyclic AMP-dependent protein kinase simulates facilitation of transmitter release underlying behavioral sensitization in Aplysia. Proc Natl Acad Sci USA 77:7492-7496.

Castellucci VF, Blumenfeld H, Goelet P, Kandel ER (1989) Inhibitor of protein synthesis blocks long-term behavioral sensitization in the isolated gill-withdrawal reflex of Aplysia. J Neurobiol 20:1-9.

Chavez-Noriega LE, Stevens CF (1994) Increased transmitter release at excitatory synapses produced by direct activation of adneylate cyclase in rat hippocampal slices. J Neurosci 14:310-317.

Cole AJ, Saffen DW, Baraban JM, Worley PF (1989) Rapid increase of an immediate early gene mRNA in hippocampal neurons by synaptic NMDA receptor activation. Nature 340:474-476.

Colina A, Malenka RC (1993) Mechanisms underlying induction of LTP in rat medial and lateral perforant paths in vitro. $\mathrm{J}$ Neurophysiol 69:1150-1159.

Crow T, Forrester J (1990) Inhibition of protein synthesis blocks longterm enhancement of generator potentials produced by one-trial in vivo conditioning in Hermissenda. Proc Natl Acad Sci USA 87:4490-4494.

Dash PK, Hochner B, Kandel ER (1990) Injection of cAMP-responsive element into the nucleus of Aplysia sensory neurons in culture that depend on new protein synthesis. J Neurosci 7:2232-2238.

Davis HP, Squire LR (1984) Protein synthesis and memory: a review. Psychol Bull 96:518-559.

Desmond NL, Levy WB (1986a) Changes in the numerical density of synaptic contacts with LTP in the hippocampal dentate gyrus. J Comp Neurol 253:466-475.

Desmond NL, Levy WB (1986b) Changes in the postsynaptic density with LTP in the dentate gyrus. J Comp Neurol 253:476-482.

Drain P, Folkers E, Quinn WG (1991) cAMP-dependent protein kinase and the disruption of learning in transgenic files. Neuron 6:71-82.

Fazeli MS, Corbet J, Dunn MJ, Dolphin AC, Bliss TVP (1993) Changes in protein synthesis accompanying LTP in dentate gyrus in vivo. J Neurosci 13:1346-1353.

Frey U, Krug M, Brodemann R, Reymann K, Matthies H (1989) Longterm potentiation induced in dendrites separated from rat's CA1 pyramidal somata does not establish a late phase. Neurosci Lett 97:135-139.

Frcy U, Huang YY, Kandel ER (1993) Effects of cAMP simulate a latc stage of LTP in hippocampal CAl neurons. Science 260:1661-1664.

Frotscher M (1991) Target cell specificity of synaptic connections in the hippocampus. Hippocampus 1:123-130.

Ghirardi M, Braha O, Hochner B, Montarolo PG Kandel ER, Dale N (1992) Roles of PKA and PKC in facilitation of evoked and spontaneous transmitter release at depressed and nondepressed synapses in Aplysia sensory neurons. Neuron 9:479-489. 
Glanzman DL, Kandel ER, Schacher S (1990) Target-dependent structural changes accompanying long-term synaptic facilitation in Aplysia neurons. Science 249:799-802

Hanse E, Gustafsson B (1992a) Postsynaptic, but not presynaptic, activity controls the early time course of LTP in the dentate gyrus. J Neurosci $12: 3226-3240$.

Hanse E, Gustafsson B (1992b) LTP and field EPSPs in the lateral and medial perforant paths in the dentate gyrus in vitro: a comparison. Eur J Neurosci 4:1191-1201.

Hanse E, Gustafsson B (1994) Staurosporine impairs both short-term and long-term potentiation in the dentate gyrus in vitro. Neuroscience $58: 263-274$

Hjorth-Simonsen A, Jeune B (1972) Origin and termination of the hippocampal perforant path in the rat studied by silver impregnation. J Comp Neurol 144:215-232.

Huang Y-Y, Kandel ER (1994) Recruitment of long-lasting and protein kinase A-dependent long-term potentiation in the CA1 region of hippocampus requires repeated tetanization. Learn Memory 1:74-82.

Huang Y-Y, Li XC, Kandel ER (1994) cAMP contributes to mossy fiber LTP by initiating both a covalently mediated early phase and macromolecular synthesis-dependent late phase. Cell 79:69-79.

Hughes P, Dragunow M (1995) Induction of immediate-early genes and the control of neurotransmitter-regulated gene expression within the nervous system. Pharmacol Rev 47:133-178.

Kaang B-K, Kandel ER, Grant SGN (1993) Activation of cAMP responsive genes by stimuli that produce long-term facilitation in $A p l y$ sia scnsory ncurons. Ncuron 10:427-435.

Krug M, Lossner B, Ott T (1984) Anisomycin blocks the late phase of LTP in the dentate gyrus of freely moving rats. Brain Res Bull $13: 39-42$.

Matthies H, Reymann KG (1993) Protein kinase A inhibitors prevent the maintenance of hippocampal long-term potentiation. NeuroReport 4:712-714.

McNaughton BL (1980) Evidence for two physiologically distinct perforant pathways to the fascia dentata. Brain Res 199:1-19.

McNaughton BL, Barnes CA (1977) Physiological identification and analysis of dentate granule cell responses to stimulation of the medial and lateral perforant pathways in the rat. J Comp Neurol 175:439-454.

Montarolo PG, Goelet P, Castellucci VF, Morgan J, KandeI ER, Schacher $\mathrm{S}$ (1986) A critical period for macromolecular synthesis in long-term heterosynaptic facilitation in Aplysia. Science 234:1249-1254.

Nazif FA, Byrne JH, Cleary LJ (1991) cAMP induces long-term morphological changes in sensory neurons of Aplysia. Brain Res 539:324-327.

Nguyen PV, Abel T, Kandel ER (1994) Requirement of a critical period of transcription for induction of a late phase of LTP. Science 265:1104-1107.

Nicoll RA, Kauer JA, Malenka RC (1988) The current excitement in long-term potentiation. Neuron 1:97-103.

Otani S, Abraham WC (1989) Inhibition of protein synthesis in the dentate gyrus, but not the entorhinal cortex, blocks maintenance of LTP in rats. Neurosci Lett 106:175-180.
Otani S, Marshall CJ, Tate WP, Goddard GV, Abraham WC (1989) Maintenance of LTP in rat dentate gyrus requires protein synthesis but not mRNA synthesis immediately post-tetanization. Neuroscience 28:519-526.

Polster MR, Nadel L, Schachter DL (1991) Cognitive neuroscience. Analysis of memory: a historical perspective. J Cognit Neurosci 3:95-116.

Qian Z, Gilbert ME, Colicos MA, Kandel ER, Kuhl D (1993) Tissueplasminogen activator is induced as an immediate-early gene during seizure, kindling, and LTP. Nature 361:453-457.

Sarvey JM, Voulalas PJ (1995) Forskolin-induced potentiation in hippocampal dentate gyrus increases phosphorylation of CREB. Soc Neurosci Abstr 21:1322.

Sheng M, McFadden G, Greenberg ME (1990) Membrane depolarization and calcium induce c-fos transcription via phosphorylation of transcription factor CREB. Neuron 4:571-582.

Soriano E, Frotscher M (1993) GABAergic innervation of the rat fascia dentata: a novel type of interneuron in the granule cell layer with extensive axonal arborization in the molecular layer. J Comp Neurol 334:385-396.

Stanton PK, Sarvey JM (1984) Blockade of LTP in rat hippocampal CA1 region by inhibitors of protein synthesis. J Neurosci 4:3080-3088.

Stanton PK, Sarvey JM (1985) The effect of high-frequency electrical stimulation and norepinephrine on cAMP levels in normal versus norepinephrine-depleted rat hippocampal slices. Brain Res 358:343-348.

Steward O (1976) Topographic organization of the projections from the entorhinal area to the hippocampal formation of the rat. J Comp Neurol 167:285-314.

Tully T, Preat T, Boynton SC, Del Vecchio M (1994) Genetic dissection of consolidated memory in Drosophila melanogaster. Cell 79:35-47.

Voulalas PJ, Sarvey JM (1995) Forskolin-induced potentiation in hippocampal dentate gyrus increases phosphorylation of mitogen-activated protein kinases. Soc Neurosci Abstr 21:601.

Weisskopf MG, Castillo PE, Zalutsky RA, Nicoll RA (1994) Mediation of hippocampal mossy fiber LTP by cAMP. Science 265:1878-1882.

Wigström H, Gustafsson B (1983a) Large long-lasting potentiation in the dentate gyrus in vitro during blockade of inhibition. Brain Res 275:153-158.

Wigström H, Gustafsson B (1983b) Facilitated induction of hippocampal long-lasting potentiation during blockade of inhibition. Nature 301:603-604.

Yin JCP, Wallach JS, Del Vecchio M, Wilder EL, Zhuo H, Quinn WG, Tully $\mathrm{T}$ (1994) Induction of a dominant-negative CREB transgene specifically blocks long-term memory in Drosophila. Cell 79:49-58.

Zalutsky RA, Nicoll RA (1990) Comparison of two forms of long-term potentiation in single hippocampal neurons. Science 248:1619-1624.

Zola-Morgan S, Squire LR, Amaral DG (1986) Human amnesia and the medial temporal region: enduring memory impairment after a bilateral lesion limited to field CA1 of the hippocampus. J Neurosci 6:29502967. 